\title{
Erratum to: Spironolactone improves endothelial dysfunction in streptozotocin-induced diabetic rats
}

\author{
Heba Adel $^{1} \cdot$ Ashraf Taye $^{1} \cdot$ Mohamed M. A. Khalifa ${ }^{1}$
}

Published online: 30 March 2016

(C) Springer-Verlag Berlin Heidelberg 2016

Erratum to: Naunyn-Schmiedeberg's Archives of Pharmacology 387: 1187-1197, 2014

DOI 10.1007/s00210-014-1048-3

Unfortunately, panel $\mathrm{b}$ in figures 4,6 and 8 of our manuscript mistakenly replicated panel a (control rats) rather than showing data from control rats treated with spironolactone. The quantitative analysis of the data shown in panel e has not been affected by this. Corrected figures with their legends are provided below. We apologize for any confusion this may have caused for readers.

The online version of the original article can be found at http://dx.doi.org/ 10.1007/s00210-014-1048-3.

Ashraf Taye

ashraf_taye70@yahoo.com

1 Department of Pharmacology \& Toxicology, Faculty of Pharmacy, Minia University, Minia 61511, Egypt 
Fig. 4 Effect of spironolactone on the endothelial nitric oxide synthase (eNOS)

immunoreactivity in rats, aortic tissues in the control and STZinduced diabetic rats. Aortic tissues from the control nondiabetic rats show positive eNOS immunoreactivity in rat aorta (a). Aortic tissues of spironolactonetreated group illustrate similar eNOS immunoreactions as in the control rat aorta (b). Aortic tissues of STZ-treated group show faint eNOS immunoreactivity (c). Aortic tissues of diabetic ratstreated with spironolactone illustrate restoring the dysregulated eNOS immunoreactivity close to that of the control rats (d). Quantification of eNOS protein area percentage (e). Data are expressed as mean \pm SEM. ${ }^{*} P<0.01$, STZ-treated group vs. control and. control + SPIRO-treated groups; ${ }^{\#} P<0.01$, STZ+ SPIRO-treated group vs. STZ-treated group
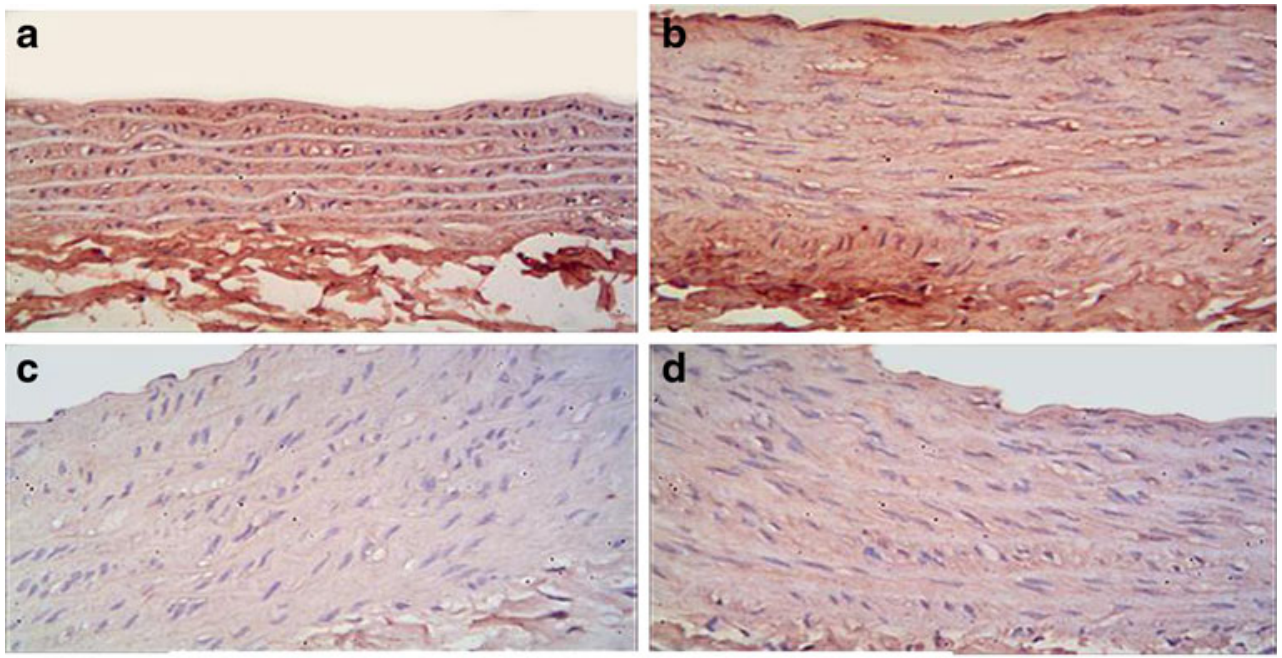

e

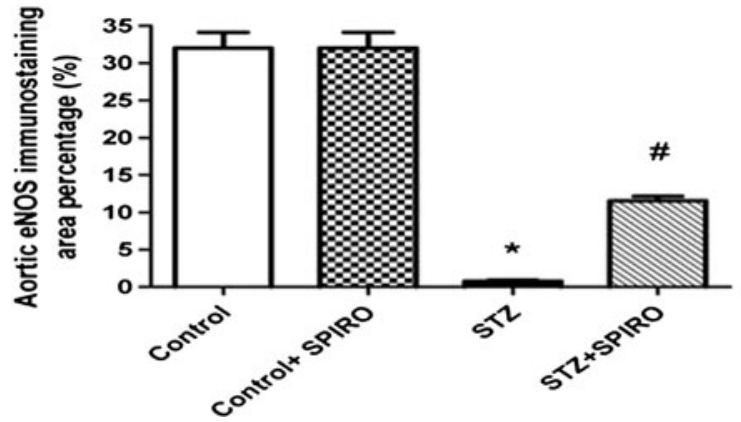


Fig. 6 Effect of spironolactone on the transforming growth factor (TGF)- $\beta$ immunoreactivity in rat aorta from control and STZinduced diabetic rats. Aortic tissues of the control rats show faint TGF- $\beta$ immunoreactivity (a). Aortic tissues of spironolactone-treated group illustrate also faint TGF- $\beta$ immunoreactivity (b). Aortic tissues of STZ-treated group show a marked immunopositive reactions of TGF- $\beta$ (c). Aortic tissues of diabetic rats treated with spironolactone could to certain extent reduced TGF- $\beta$ immunoreactivity (d). Quantification of TGF- $\beta$ protein area percentage (e). Data are expressed as mean \pm SEM. ${ }^{*} P<0.01, \mathrm{STZ}$-treated group vs. control and. control + SPIROtreated groups; ${ }^{*} P<0.01$, STZ+ SPIRO-treated group vs. STZtreated group
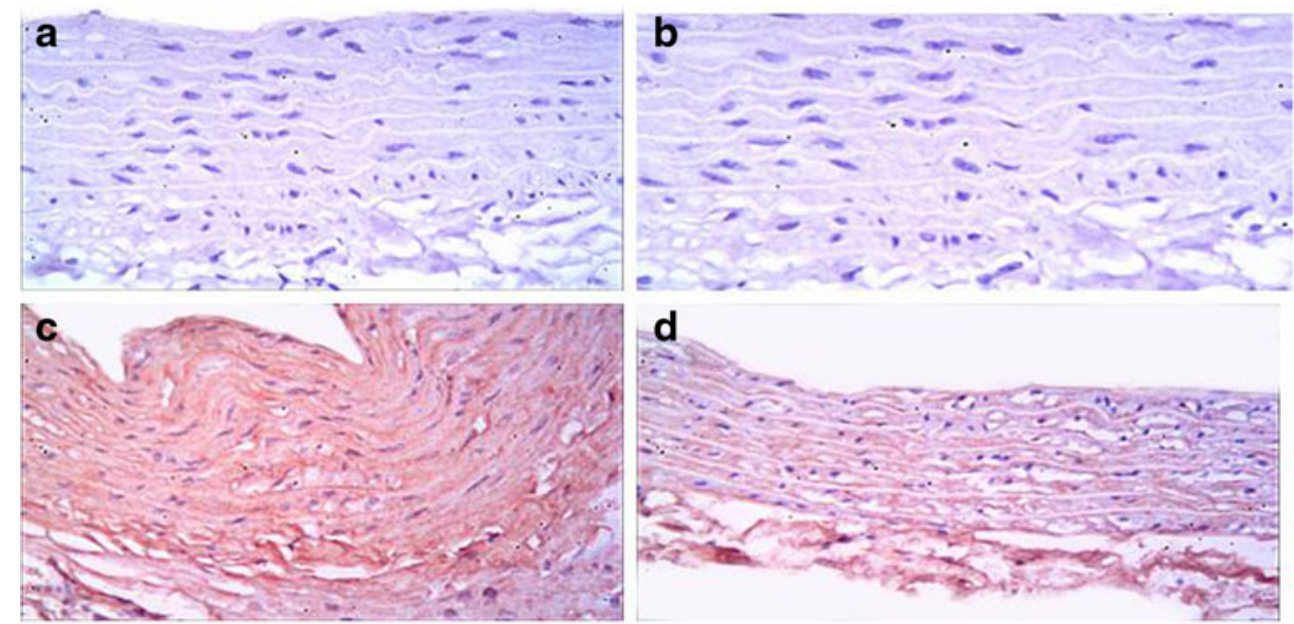

e

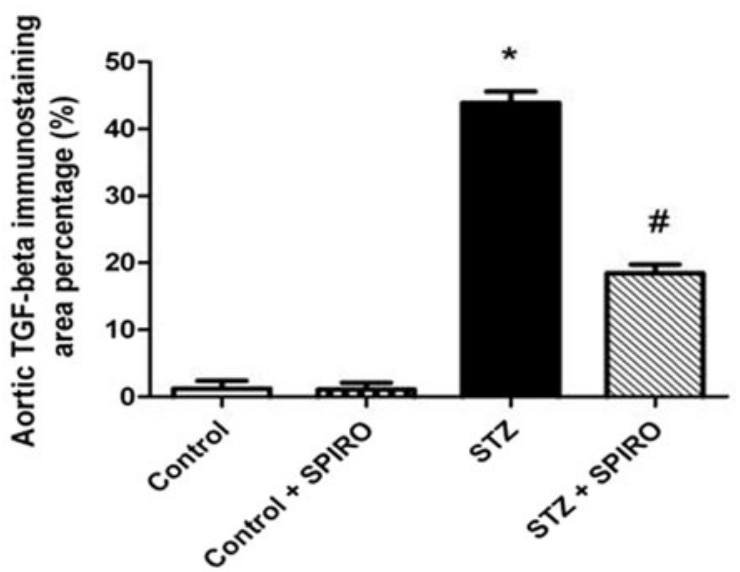



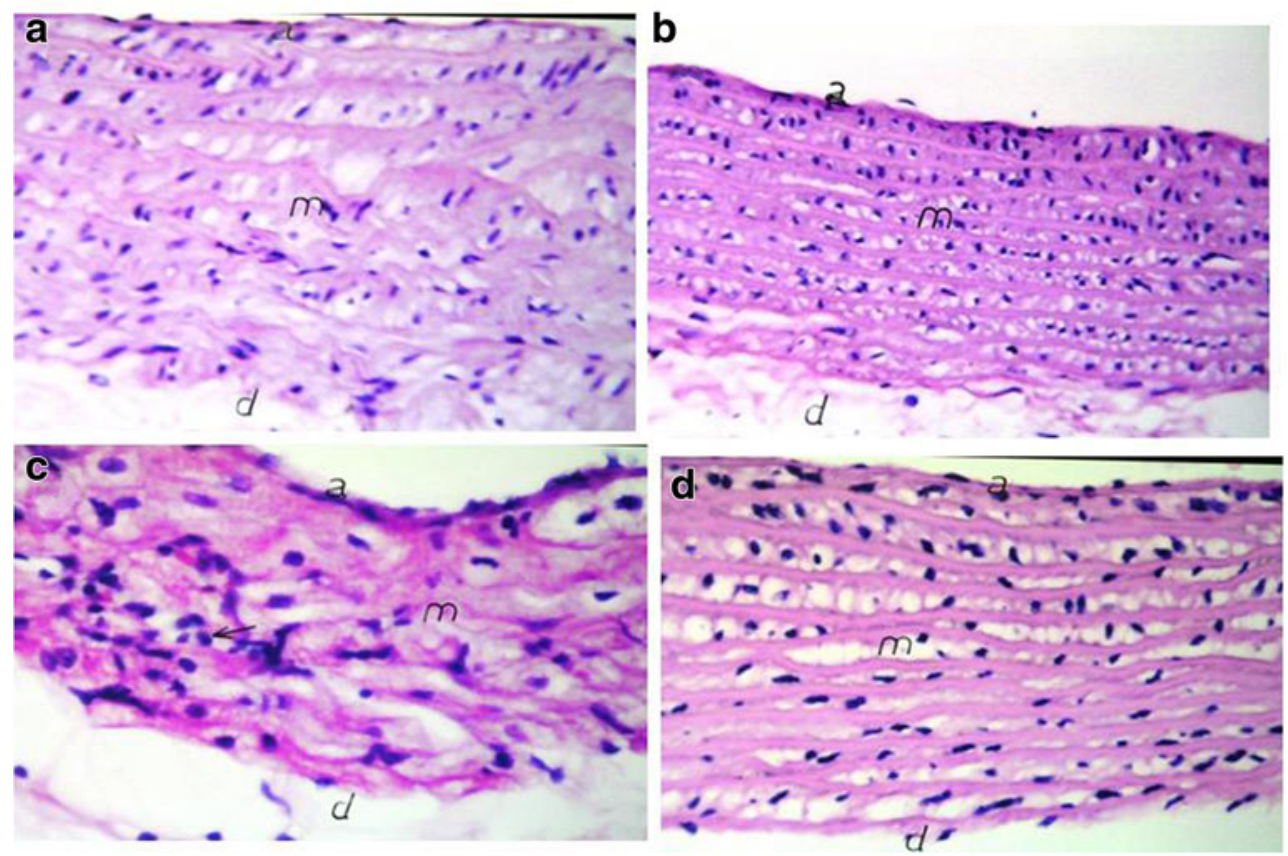

Fig. 8 Effect of spironolactone on histopathological alterations of STZinduced diabetic rats and control aortic tissues stained with Hematoxylin and Eosin (x 80). Aortic tissues of the control group show no histological changes with normal tunica intima $(a)$ media $(m)$ and adventitia $(d)$, (a). Aortic tissues of the control rats treated with spironolactone reveal no histological alterations similar to a certain extent that of the control

group (b). Aortic tissues of STZ- treated group reveal marked alterations in aortic structure (m) with edema in adventitia (d) and focal inflammatory cells infiltration in the media (arrow) (c). Aortic tissues of diabetic group treated with spironolactone illustrate a marked improvement in the abnormalities observed in diabetic rat aorta (d) 